\title{
0 mundo envelhece: é imperativo criar um pacto de solidariedade social
}

\author{
The world is ageing: a pact of social solidarity is an imperative
}

Alexandre Kalache ${ }^{1}$

${ }^{1}$ Programa de

Envelhecimento eSaúde, Organização M undial de Saúde. 20, AvenueAppia, $\mathrm{CH}-1211$, Geneva, Switzerland.

kalachea@who.int
Abstract This text presents the key topics, which guided the discussionsabout demographic change and the resultant public health implications. With the ageing of the societies, the health problems of the elderly put pressure on health and social security systems. With regard to work and social wellbeing, there are three important sub-topics: the labor market and the elderly; social security and questions related to shelter for the aged population. The ageing process normally occurs in good health conditions unless there is disease. In addition, thescientific and technological achievements in the health area allow for a better quality of life for the elderly. This is why preventive strategies over thelifespan turned more important for meeting today's challenges and increasingly those of tomorrow. As refers to innovation and markets, longevity creates numberless opportunities especially in terms of new products and markets. On the other hand, the term "productive ageing" has been widely used for defining the increasing trend towards a life style in an ageing society. Finally we will approach the topic ageing and development showing that the demographic shift is already one of the most urgent global problems, being addressed by public policies both in the developed and developing countries.

Key words Demography, Ageing, Health care system, Social assistance
Resumo Este texto apresenta os eixos que têm norteado as di scussões no campo da Demografia e que trazem implicações para a Saúde Pública. Os problemas de saúde entre idosos desafiam os sistemas de saúde e de seguridade social. Em relação a trabal ho ebem- estar social, três subtemas se destacam: o idoso e o mundo do trabalho; a previdência equestões relativasà habitação para uma população idosa. 0 processo de envelhecimento normalmente está associado a um bom nível de saúde, a menos que haja doença. Além disso, os avanços na ciência da saúde e tecnologia tornaram possível uma melhor qualidade de vida na velhice. Para isso, estratégias de prevenção ao longo de todo 0 curso de vida tornaram-se mais importantes para resolver os desafios dehojee, de forma crescente, os de amanhã. Em relação à inovação e mercado, a longevidade traz numerosas oportunidades, especialmente em termos do desenvolvimento de novos produtos e a descoberta de novos mercados. Por outro lado, o termo "envelhecimento produtivo" tem sido largamente utilizado para significar uma tendência crescentedeestilo de vida em uma sociedade que envelhece. Finalmente, o binômio enve Ihecimento/desenvolvimento éabordado, apontando que a transição demográfica já é um dos mais urgentes problemas mundiais, tornando-se tema para políticastanto nospaíses desenvolvidosquando em desenvolvimento.

Palavras-chave Demografia, Envelhecimento, Sistema de saúde, Assistência social 
Introdução

O envel hecimento inexorável de uma perspectiva internacional implica a acentuação das desigualdades entre países desenvolvidoseem desenvolvimento, bem como entre pobres e ricos num mesmo país. As implicações sociais destas desigualdades não têm precedentes ese manifestam particularmente nas diferenças de nível de saúde, levando a desafios colossais para os futuros cenáriospolíticos esociais. Daí a necessidade de reforçar a solidariedade entre subgrupos de uma mesma população, assim como a nível internacional.

Em resposta a estes desafios, foi criada em 2005 a Associação Mundial de Demografia, com base na Universidade de St. Gallen, Suíça. Desde então, a Associação realiza a cada mês de agosto um congresso que reúne especialistas dos mais reputados de todos os campos do conhecimento. O terceiro destes congressos, em 2007, teve como tema central o estabelecimento de uma "solidariedade planetária" baseada num pacto desolidariedade distributiva entre gerações e entre nações.

Este texto apresenta os eixos que estruturaram as discussões deste encontro interdisciplinar de especialistas: trabal ho e bem-estar social; saúde; inovação emercado; estilo de vida e sociedade eo binômio envelhecimento/desenvolvimento.

\section{Trabalho e bem-estar social}

Sob este tópico, três subtemas se destacaram: 0 idoso e o mundo do trabalho; a previdência e questões relativas à habitação para uma população idosa.

As sociedades modernas têm testemunhado uma transformação na maneira de compreender o trabalho. Por outro lado, o setor da previdência e seguridade social está se desarticulando. Como resultado, as expectativas individuais estão mudando radicalmente. A informalidadelaboral tem crescido de modo preocupante, sobretudo nos países em desenvolvimento. A sustentabilidade dos sistemas de seguridade social tem sido colocada em questão. A fragilidadetanto das condições culturais quanto da coesão social que permite 0 bem-estar pessoal tem se tornado muito evidente. $\mathrm{Na}$ raiz destes desafios estão as dramáticas mudanças demográficas que estão ocorrendo virtualmente em todo o mundo. E tais desafios se intensificaram tendo em vista queo envelhecimento populacional continuará - nos países em desenvolvimento de forma até mais acelerada do que nosúltimos anos. Háainda quese considerar que a expectativa de vida, sobretudo dos indivíduos com mais de 60 anos, tem crescido continuamente nas últimas décadas e, na opinião de vários especial istas, continuará aumentando. Hoje, por exemplo, uma mulher no $\mathrm{N}$ orte europeu espera aos 60 anos viver outros trinta - ou seja, um terço a mais do total de vida. Tudo isso impõe a necessidade de aprofundar a compreensão da interdependência das práticas de trabalho, situações de moradia, bem-estar pessoal e coesão social.

0 mercado de trabalho globalizado está se tornando um campo de batalha; uma batalha por talentos, habilidades especificas e por cérebros. Portanto, preservar a contribuição daqueles quedetêm conhecimento eexperiência deveria ser uma prioridade. No entanto, o inverso tem se dado em vários países onde a idade média da aposentadoria tem diminuído. Com as taxas de fecundidade declinando emuitos setores promovendo a aposentadoria precoce (especialmenteem relação ao trabalho qualificado), uma necessidade de trabalhadores qualificados pode ser observada em muitos países industrializados, particularmenteno setor deserviços. Na maioria dos países europeus, a força de trabalho irá começar a se contrair nos próximos vinte anos - a menos que políticas visando aumentar o número de imigrantes se intensifique - o que tem gerado movimentos antagônicos fortíssimos em vários países, traduzindo-se em xenofobia e manifestações racistas contundentes. N este contexto, não apenas o debate político deve ser intensificado, políticas públicas ajustadas, mas também 0 mundo de negócios tem que repensar suas políticas em relação aos trabalhadores idosos.

Atualmente, à medida que se dissemina uma cadeia produtiva globalizada, estão se desenhando novas possibilidades de qualificação da força de trabalho, novas estratégias para formar e recrutar os trabalhadores do futuro e novas maneiras para lidar com a crescente necessidade de especialização.

0 mundo todo está envelhecendo. Esteé um fato que as nações estão começando a compreender à medida que buscam caminhos para manter seus cidadãos idosos socialmente e economicamente integrados eindependentes. Repensar a aposentadoria pode ser um caminho através do qual parceiros sociais podem fortalecer as pensões públicas, encorajar a poupança privada e sistemas privados de pensão e oferecer oportunidades para a continuidade da vida de trabal ho eemprego - desdeque sistemas de proteção social para os mais pobres e excluídos sejam prioridades explícitas das políticas sociais. 
Por outro lado, o envelhecimento populacional vai trazer grande demanda por uma política de habitação que forneça soluções para pessoas idosas. M oradia é uma das dimensões que definem a qualidade de vida na velhice. As pessoas idosas passam 60 a 70\% de seu tempo em casa, muito mais do que outros grupos etários. Portanto, questões de ventilação, esgoto sanitário, recoIhimento de lixo, segurança, áreas externas bem mantidas e que favoreçam a socialização e manutenção e adaptação ambiental influenciam a saúde física e mental, com um significativo impacto sobreo bem-estar. Portanto, éimperativo o desenvolvimento de uma política de habitação visando a população idosa. A mesma deve estar intimamente associada a uma política de transporte público abrangente e apropriado aos idosos.

\section{Saúde}

À medida que as sociedades envel hecem, os problemas de saúde entre idosos desafiam os sistemas desaúdee deseguridadesocial. Enfermidade não éuma conseqüência inevitável da velhice, nem tampouco está limitada a este contingente populacional. Envelhecimento está associado a um bom nível de saúde, a menos que haja doença. Além disso, os avanços na ciência da saúde e tecnologia tornaram possível, para aqueles com poder aquisitivo ou cobertos por seguros adequados - públicos ou privados - uma melhor qualidade de vida na velhice. Para isso, estratégias de prevenção ao longo de todo o curso de vida tornaramse mais importantes para resolver os desafios de hojee, de forma crescente, os de amanhã.

Os avanços na pesquisa médica etecnológica aumentaram muito nossa capacidade de tratar as doenças crônicas. No entanto, os sistemas nacionais de saúde enfrentam dificuldades para tornar estes novos tratamentos acessíveis à maioria das pessoas. Entre outros problemas, estratégias pensadas apenas para um curto prazo e conten ção decustos têm dificultado a disponibilização de novos tratamentos e contribuem para as disparidades no acesso até mesmo nos países industrializados.

Faz-se necessária uma abordagem destes desafios de forma abrangente e sistêmica. São desafios que incluem o financiamento das ações de saúde e outras questões intersetoriais e vão até a educação do paciente e dos provedores de serviços de saúde. Outros fatores podem ajudar os governos a atingir o controle da morbidade e mortalidade por doença crônica em prazo mais longo. Tais medidas podem em longo prazo levar à economia de recursos e, ao mesmo tempo, garantir o melhor às expectativas dos pacientes $e$ dos cidadãos.

À medida que as tendências demográficas aceleram, há um aumento na prevalência de doenças crônicas, o que implica a urgência de priorizar a prevenção em todos os países. Hoje, muitos sistemas de saúde são orientados pelo imediatismo, com ênfase no cuidado agudo, e não na prevenção e no cuidado crônico. Os dados epidemiológicos mostram claramente a mudança do perfil de agudo para crônico - mas o setor de prestação de serviços ainda vê uma doença crônica como se fosse um episódio isolado e agudo. N ão se pode tratar hipertensão, diabetes ou artrose como se fossem episódios de diarréia aguda ou uma gripe. As políticas devem considerar um espectro mais amplo de estratégias preventivas que incluam não apenas as técnicas de promoção da saúde tradicionais mas também o uso de práticas alternativas desde que comprovadamente efetivas. 0 uso de vacinas visando o grupo maisidoso - antigripal, pneumocócica, antitetânica- também deveser ampliado. Acima detudo, é imprescindível investir em uma cidadania informada por uma literatura em saúde. Uma abordagem mais ampla da prevenção pode levar a um aumento em anos de vida ganhos eà redução da carga financeira da doença crônica.

No campo de saúdemental, o primeiro emais importante problema entre os idosos é a depressão. As causas são inúmeras e podem ser encontradas não só em fatores genéticos, biológicos ou psicológicos, mas também em circunstâncias sociais e ambientais. Mudanças drásticas na situação de moradia, aposentadoria, a perda de um cônjuge ou amigo, ansiedade sobre a perda de capacidades emedo denão ser capaz de lidar com o que no passado teria sido apenas um aborrecimento passageiro pode destruir a percepção de bem-estar. Urge, portanto, a adoção de medidas intersetoriais. A depressão também leva ao isolamento, a uma contínua perda de autoconfiança, podendo, em casos extremos, levar ao suicídio.

\section{I novação e mercado}

A longevidade traz numerosas oportunidades, especialmente em termos do desenvolvimento de novos produtos e a descoberta de novos mercados, principalmente o mercado imobiliário, de transporte e do setor turístico. No entanto, devido ao fato de que a ciência ainda tem mais a ofe- 
recer, 0 aprendizado de uma vida longa e o enveIhecimento cognitivo estão no cerne de um mercado em rápida expansão - o mercado de bens tecnológicos. Em quase todos os países industrializados, a geração dos +50 representa o grupo populacional com não apenas a maior taxa de crescimento, mas também o grupo com maior poder de compra. Portanto, soluções inovadoras para este novo grupo-alvo são uma chave para o sucesso na maioria das indústrias.

Idosos que vivem em regiões rurais enfrentam maiores obstáculos de acesso a serviços de saúde de qualidade. Este acesso difícil, quando combinado com um baixo status socioeconômico, contribuem para aumentar as disparidades na saúde das populações de idosos de área rural. N esta área de cobertura de populações isoladas, a tecnologia de informação poderá oferecer soluções inovadoras.

Opções de residência assistida têm se tornado uma solução para moradia, por oferecerem ambientes com suporte para idosos, principalmente na Europa e nos Estados Unidos. Dentro destecontexto, a integração do design com o planejamento do atendimento às necessidades dos idosos deve ser valorizada.

A valorização da juventude é uma questão crítica em nossa sociedade. No mercado de trabalho, os jovens são considerados mais eficientes, mais capazes, mais resistentes ao estresse, mais fáceis de se integrar e mais "mente-aberta". Os idosos procuram parecer e agir como os jovens para serem valorizados. Esta tendência também implica a existência de uma percepção do que significa ser "velho" nesta sociedade. Portanto, para um envelhecimento bem-sucedido, torna-se vital reforçar atitudes positivas, ser capaz de se adaptar a circunstâncias sociais caracterizadas por mudanças, aprender continuamente, ter a capacidade de adquirir novas habilidades incorporando novos conceitos e tecnologias e, mais importante, ter acesso à informação para tomar decisões.

\section{Estilo de vida e sociedade}

O termo "envelhecimento produtivo" tem sido largamenteutilizado para significar uma tendência crescente de estilo de vida em uma sociedade que envelhece. Os idosos estão promovendo e organizando estilos de vida que permitam sua participação ativa nos avanços econômicos esociais de seus países, de modo a assegurar que eles sejam considerados mais contribuintes do que dependentes. Esta participação tem o benefício adicional de contribuir para melhorar a sua própria saúde, independência e bem-estar. M ais do que isso, um "envelhecimento produtivo" éapenas um lado da moeda: podemos também repensar e redefinir nossas relações intergeracionais nos contextos sociais e econômicos. Especificamente, as sociedades industrializadas devem experimentar grandes mudanças na distribuição de riquezas entre gerações, mudanças na representação política eatéem matérias como o significado e o valor de uma expectativa de vida tão estendida.

A revolução demográfica alterou a pirâmide populacional das sociedades modernas e levou a uma transição para a família que envel hece. Além do envelhecimento da sociedade, também testemunhamos uma mudança nas estruturas familiares. Hojeexistem diferentes tipos defamília. 0 envelhecimento populacional adiciona complexidade em virtude do aumento do tempo de convívio entre gerações. Hoje, é comum existirem famílias de três, quatro e até mesmo cinco gerações. Portanto, surge o desafio de lidar com estas mudanças.

Cada família, em cada país, tem sua cultura própria para solucionar este problema. Embora as normas filiais possam ser fortes, haverá muitas variações em como estas normas são aplicadas. Combinado com estas transformações demográficas emudanças nas vidas familiares, também temos que considerar o impacto das mudanças sociais e tecnológicas, a migração interna e externa, as mudanças nas políticas sociais e as mudanças nas preferências das famílias por tipo de cuidado.

Tais transformações influenciarão cada vez mais os laços familiares entre as gerações. Os contextos sociais de diferentes regimes, a cultura familiar e os estágios da vida e os recursos pessoais darão significado às relações familiares intergeracionais, determinando as trocas e o suporte quando os membros familiares idosos necessitarem de cuidados.

\section{Envelhecimento e desenvolvimento}

Ao contrário dos países desenvolvidos que se tornaram ricos antes de envel hecer, os países em desenvolvimento estão envelhecendo antes de enriquecerem. Este fato traz um imenso desafio para os países em desenvolvimento em muitas áreas, incluindo a seguridade social e o crescimento econômico. Além disso, as populações em 
idade de crescimento nos países em desenvolvimento irão aumentar a população mundial a um nível insustentável no decorrer do próximo sé culo. Para enfrentar este desafio, é essencial existir uma cooperação internacional devido ao fato da grande associação entre os problemas sociais eecológicos.

O Plano Internacional de Ação sobreo EnveIhecimento de Madri, adotado por ocasião da segunda assembléia mundial sobreenvelhecimento, é o primeiro compromisso internacional que reconheceespecificamente o potencial dosidosos para contribuir com o desenvolvimento de suas sociedades. N estedocumento, mais de 160 países se comprometem a incluir o envel hecimento em todas as suas políticas de desenvolvimento sociais e econômicas ereduzir à metade o envelhecimento com pobreza até 2015, alinhando-se com as metas de desenvolvimento do milênio.

Um ponto central da declaração que acompanhava este documento é o compromisso de eliminar todas as formas de discriminação, incluindo a discriminação por idade. Foi também reconhecido que as pessoas que envelhecem devem ter direito à autorealização, saúde, seguridade e partici pação ativa na vida econômica, social, cultural e política de suas sociedades. Comprometeram-se a garantir o respeito à dignidade dos idosos e eliminar todas as formas de negligência, abuso e violência. 0 desafio agora, cinco anos depois destes compromissos, é garantir que os governos cumpram estes compromissos.

A transição demográfica é um dos mais urgentes problemas mundiais, tornando-se tema para políticas tanto nos países desenvolvidos quando em desenvolvimento. Os cenários de seguridade e sistemas de saúde são assustadores, com um potencial impacto negativo na solidariedadesocial. $\mathrm{Na}$ Europa, a infertilidadetem emergido como um importante aspecto da saúde, enquanto que nos países em desenvolvimento os problemas socioeconômicos mascaram a saúde materno-infantil. No entanto, a sobrevivência da humanidade depende das futuras gerações. Devido à migração e ao envelhecimento de nossa sociedade, precisamos nos preocupar com as futuras gerações. 